\title{
Um enlace entre ciência e literatura: \\ o Somnium de Johanes Kepler
}

\author{
Gustavo Santos Giacomini \\ Doutorando em História Social - USP \\ gugiacomini@hotmail.com
}

Como citar este artigo: Giacomini, G. S. "Um enlace entre ciência e literatura: o Somnium de Johanes Kepler”. Khronos, Revista de História da Ciência, no 9, pp. 68-80. 2020. Disponível em <http://revistas.usp.br/khronos $>$. Acesso em $\mathrm{dd} / \mathrm{mm} /$ aaaa.

Resumo: No início da idade moderna, novas concepções astronômicas e físicas fomentaram ideias relativas a outros mundos e vida extraterrestre, de modo que forneceram um território inédito para a imaginação científica e literária, a saber, o novo mundo na Lua. Em vista disso, empregamos a obra Somnium, de Johannes Kepler, como vestígio e indício, com a finalidade de examinar a ligação existente entre ciência e literatura no princípio da modernidade. Procuramos destacar como as ideias relativas à pluralidade e habitabilidade dos mundos e à possibilidade de viagens lunares e cósmicas são exploradas nesse contato íntimo entre ciência e literatura. Nosso objetivo é identificar as persistências e metamorfoses dos resquícios na obra de Kepler e, com isso, delinear as linhas primevas de um novo gênero literário, isto é, a ficção científica. Ao propor um exercício de hermenêutica histórica sobre o Somnium, pretendemos levar em conta, pelo menos em parte, as transmissões e recepções do tema enquanto trajetória de uma ideia no tempo.

Palavras-chave: Ficção científica; ciência e literatura; Somnium; Johanes Kepler. 


\title{
A link between science and literature: the Somnium by Johanes Kepler
}

\begin{abstract}
In the beginning of the modern age, new astronomical and physical concepts fostered ideas related to other worlds and extraterrestrial life, so that they provided an unprecedented territory for the scientific and literary imagination, namely, the new world on the Moon. In view of this, we choose Somnium, by Johannes Kepler, as a trace and evidence, in order to examine the connection between science and literature at the beginning of modernity. We seek to highlight how ideas related to the plurality and habitability of the worlds and the possibility of lunar and cosmic travel are explored in this intimate contact between science and literature. Our goal is to identify the persistence and metamorphosis of the remains in Kepler's work and, with this, to outline the primeval lines of a new literary genre, that is, science fiction. By proposing an exercise in historical hermeneutics on Somnium, we intend to take into account, at least in part, the transmissions and receptions of the theme as the trajectory of an idea in time.
\end{abstract}

Keywords: Science fiction; Science and literature; Somnium; Johanes Kepler.

No início da idade moderna, um gênero narrativo que retratava viagens era muito popular. Independentemente de sua intenção original como sátira, didatismo, utopismo ou simples exotismo cheio de maravilhas, certas "viagens imaginárias” do século XVII podem ser consideradas como um dos primeiros exemplos de ficção científica ${ }^{1}$. A razão é simples: eram narrativas ficcionais que, diferentemente das muitas fantasias imaginativas que as precederam, eram racionalmente especulativas e baseadas na "nova filosofia" e, em especial, na astronomia copernicana $^{2}$.

A astronomia copernicana consiste na construção de uma cosmologia nova baseada nos dados fornecidos pela astronomia de Ptolomeu. Além disso, tal cosmologia está fortemente ligada a algumas teses fundamentais do aristotelismo, são elas: o universo é perfeitamente esférico e finito, já que essas propriedades são atribuídas justamente aos corpos divinos; o movimento circular é característica inerente das esferas, com exceção ao Sol que é imóvel devido a sua natureza divina ${ }^{3}$.

O sistema copernicano foi chamado de heliostático, ao invés de heliocêntrico, pois Copérnico não faz coincidir o centro do universo com o Sol, mas com o ponto central da órbita

${ }^{1}$ Conferir a introdução de ATKINSON, Geoffroy. The Extraordinary Voyage In French Literature Before 1700. New York: Columbia University Press, 1920, p. IX-XIII.

2 EVANS, Arthur B. The Origins of Science Fiction Criticism: From Kepler to Wells. Science Fiction Studies, Vol. 26, No. 2, 1999, p. 165.

${ }^{3}$ ROSSI, Paolo. O Nascimento da Ciência Moderna na Europa. Bauru: EDUSC, 2001, p. 115-121. 
terrestre. Ademais, introduz, como em Ptolomeu, uma série de círculos volvendo em torno de outros círculos e atribui à Terra (além do movimento de rotação ao redor do seu eixo e de translação ao redor do Sol) um terceiro movimento de declinação para justificar a invariabilidade do eixo terrestre com relação à esfera das estrelas fixas ${ }^{4}$.

A admissão do movimento terrestre e a aceitação do novo sistema implicavam não só uma reviravolta da astronomia e da física, mas também uma modificação das ideias a respeito do mundo, bem como uma nova avaliação da natureza e do lugar do homem nela. Isso fomentou, em particular, a conjecturação sobre outros mundos e vida extraterrestre. De modo que forneceu um novo território para a imaginação, a saber, o novo mundo na Lua.

Esta breve análise pretende destacar alguns temas e elementos relacionados ao advento desse novo modelo narrativo presentes na obra Somnium, de Johannes Kepler, considerada a primeira obra de viagem científica à Lua. Não se trata aqui de desenvolver reflexões de caráter estético, estilístico ou literário, ou de recuperar o trajeto filosófico perfilado pelo escritor. Tratase de um exercício exploratório de hermenêutica histórica, procurando identificar elementos relevantes para uma futura interpretação do surgimento da ficção científica nessa forma primeva. Para tanto, tomamos Carlo Ginzburg como guia e inspirador nesta tarefa, pois ao propor o uso de Logosformel nos permite refletir sobre a transmutação que as ideias perfazem no tempo ${ }^{5}$. Ademais, se move como o cavalo em uma partida de xadrez, de modo imprevisível, saltando de uma disciplina para a outra, de um conjunto textual para o outro, e não como "as majestosas torres disciplinares [que] se deslocam implacavelmente em linha reta". ${ }^{6}$

\section{Ficção científica, ciência e literatura}

A linguagem está no centro de toda atividade humana. "É ela que nos lança ao que ela significa; ela se dissimula a nossos olhos por sua operação mesma; seu triunfo é apagar-se e darnos acesso, para além das palavras, ao próprio pensamento do autor, de tal modo que retrospectivamente acreditamos ter conversado com ele sem termos dito palavra alguma, de espírito a espírito"7. A linguagem se torna, dessa forma, como que um elemento praticamente invisível de sobredeterminação da experiência humana, muito embora ela tenha uma existência concreta e ilimitada. As potencialidades do homem só fluem sobre a realidade através das fissuras abertas pelas palavras ${ }^{8}$. Falar, nomear, conhecer, transmitir, esse conjunto de atos se formaliza e se re-

${ }^{4}$ Cf. KOYRÉ, Alexandre. Do mundo fechado ao universo finito. Rio de Janeiro: Forense Universitária, 2006, p. 28-54.

${ }^{5}$ GINZBURG, Carlo. Medo, reverência, terror. São Paulo: Companhia das Letras, 2014, p. 12.

${ }^{6}$ GINZBURG, Carlo. Nenhuma ilha é uma ilha. São Paulo: Companhia das Letras, 2007, p. 13-15.

${ }^{7}$ MERLEAU-PONTY, Maurice. A prosa do mundo. São Paulo: Cosac Naify, 2012, p. 38-39.

8 Idem, p. 33-36. 
produz incessantemente por meio da fixação de uma regularidade subjacente a toda ordem social: o discurso. A palavra organizada em discurso incorpora em si, desse modo, toda espécie de hierarquias e enquadramentos de valor intrínsecos às estruturas sociais que emanam9. Maior, pois, do que a afinidade que se supõe existir entre as palavras e o real talvez seja a homologia que elas guardam com o ser social.

Dentre as muitas formas que assume a produção discursiva, a que nos interessa aqui, a que motivou este trabalho, é a literatura. A existência da literatura não é a sobrevivência morta de um ser alienado que se oferece simultaneamente à realidade vivencial de uma época posterior. A literatura é, antes, "uma função da preservação e da transmissão espiritual e por isso introduz em cada presente sua história oculta" ${ }^{\prime \prime}$. Assim, a obra literária ocupa seu lugar na consciência de todos. Pertence ao "mundo". Além disso, o mundo que uma obra literária atribui a si mesma pode estar muito distante e afastado do mundo original ao qual a obra falou. Não se trata mais do mesmo mundo, portanto. Mas, mesmo assim, o sentido normativo contido no conceito de literatura significa que as obras incluídas nela continuam falando, mesmo que o mundo a que falam seja completamente diferente ${ }^{11}$.

Do modo de ser da literatura participa toda a tradição feita pela linguagem, não somente os textos poéticos, religiosos, jurídicos, econômicos, públicos e privados de toda classe, mas também os escritos em que se elaboram e interpretam cientificamente esses textos transmitidos e, consequentemente, todo o conjunto das ciências ${ }^{12}$. Por isso, o modo de ser da literatura tem algo de peculiar e incomparável; ela impõe uma tarefa específica para transformar-se em compreensão. A escrita, e a literatura enquanto participa dela, "é a compreensibilidade do espírito de tal modo despojada que se situa no que há de mais estranho. (...) Desde o momento em que é decifrada e lida, a tradição escrita é de tal modo espírito puro que nos fala como se estivesse presente"13. Assim, a capacidade de compreender realiza a pura atualidade do passado.

Desse modo, o estudo da literatura conduzido no interior de uma pesquisa historiográfica (em especial, em uma perspectiva de História das Ideias) preenche-se de significados peculiares. Já que a literatura moderna é uma fronteira extrema do discurso, então, mais do que o

\footnotetext{
${ }^{9}$ Daí porque o discurso se articula em função de regras e formas convencionais, cuja contravenção esbarra em resistências firmes e imediatas. Cf. FOUCAULT, Michel. A ordem do discurso. São Paulo: Edições Loyola, 1999, p. 6-33.

${ }^{10}$ GADAMER, Hans-Georg. Verdade e método I. Petrópolis: Vozes, Bragança Paulista: Editora Universitária São Francisco, 2015, p. 227.

${ }^{11}$ Cf. Idem, p. 227-228.

12 "A ciência não está destinada a um outro mundo, mas a este; ela fala, afinal, das mesmas coisas que vivemos". (MERLEAU-PONTY, 2012, op. cit., p. 45-46) “A forma da literatura convém em geral a toda investigação científica, na medida em que esta se encontra essencialmente vinculada ao caráter da linguagem (Sprachlichkeit). A capacidade que tem tudo que pertence à linguagem de aceder à escrita circunscreve o sentido mais vasto da literatura". (GADAMER, 2015, op. cit., p. 228)

13 Idem, p. 230. Cf. MERLEAU-PONTY, 2012, op. cit., p. 43. "é que ela [a linguagem] me transformou e tornou-me capaz de compreendê-la".
} 
testemunho da sociedade, ela deve trazer em si a revelação dos seus focos mais candentes de tensão. Sendo um produto do desejo, seu compromisso é maior com a fantasia do que com a realidade. Preocupa-se com aquilo que poderia ou deveria ser a ordem das coisas, mais do que seu estado real. Nessa perspectiva, o gênero de ficção científica se sobreleva, pois envolve estratégias retóricas no emprego de uma racionalidade de algum modo científica com o objetivo de suspender a crença dos leitores e assim levá-los a um estado de coisas fantástico ${ }^{14}$. Essa estratégia, do ponto de vista do escritor, muitas vezes exige que os participantes ficcionais sejam deslocados no tempo ou no espaço, ou desorientados idealmente diante de alguma inovação hipotética. O desnorteamento dentro da fantasia e na mente do leitor, na medida em que ele se envolve na situação ativa, cria as condições para a sátira ${ }^{15}$, de modo que as noções de senso comum do que constitui a realidade não parecem se aplicar ao estado de coisas fantástico. Assim, em muitas fantasias satíricas da ciência, uma ordem social (ou caos) aparentemente improvável, às vezes o resultado lógico de uma descoberta tecnológica imaginada, desloca o que geralmente é pensado como realidade social e a consequente deformação revela aspectos da verdadeira natureza da ordem social existente. A lógica científica, em outras palavras, não se situa simplesmente entre fantasia e realidade, mas também pode indicar uma resposta satírica inserida entre as duas.

Uma interpenetração do mundo real e um estado de coisas aparentemente fantástico são características essenciais de toda ficção científica, mais especialmente da ficção científica satírica. E esse fato deve qualificar qualquer hipótese sobre os propósitos de estabelecer uma ilusão de plausibilidade. A explicação mais ou menos científica oferecida pelo escritor de ficção científica para explicar o mundo de sua fantasia reconhece uma realidade fora da ficção. Contudo, às vezes, o próprio reconhecimento pode servir a uma intenção irônica. Nas palavras de Edmund Crispin, "quase todo o aparato [explicativo] pode constituir um ataque horrível não apenas à probabilidade, mas também à possibilidade"16, com o objetivo de expor os limites da realidade reconhecida.

O exemplo da tradição literária das viagens cósmicas $^{17}$, ou mais exatamente das viagens científicas à Lua, é paradigmático. Frequentemente, em tom didático, esses relatos são vistos sob

${ }^{14}$ Para um debate mais preciso e uma apresentação detalhada, conferir o prefácio e o primeiro capítulo da obra clássica de Robert M. Philmus: PHILMUS, Robert Michael. Into the Unknown: The Evolution of Science Fiction from Francis Godwin to H. G. Wells. Berkeley and Los Angeles, California: University of California Press, 1983.

${ }^{15}$ Acerca das sátiras, as palavras de Leon Kossovitch são esclarecedoras: "a sátira, como gênero, tem muitas vozes, vácua a persona, ridículas, invertidas, dissonantes e mesmo uníssonas". Assim, com suas diferentes vozes, a adaptação é fundamental a ela. A personagem satírica acredita na não-realidade, logo, na representação fantástica dos fatos, e define a vida por comédia, fruto da mesma ilusão. Cf. Leon Kossovitch, Prefácio à obra de HANSEN, João Adolfo. A Sátira e o Engenho, Gregório de Matos e a Babia no século XVII. São Paulo: Editora Unicamp, 2005.

${ }_{16}$ CRISPIN, Edmund. Science Fiction. Times Literary Supplement, Oct. 25, 1963, p. 865.

17 Há diversas formas de nomear esses tipos de viagens. Os mais comuns são "viagens imaginárias" e "viagens extraordinárias". Contudo, seguimos a proposta de Marjorie Hope Nicolson que prefere a nomenclatura "viagens cósmicas", uma vez que "elas conduzem não aos postos avançados da civilização em 
uma perspectiva lunar da Terra ou são descobertos em sociedades e instituições mundiais lunares que se tornam a medida de suas contrapartes sublunares. Essa temática se popularizou a partir do século XVII. Os autores de viagem cósmica são descendentes de tradições literárias que remetem a Luciano e outros escritores clássicos e em adaptações dessas fontes clássicas feitas por

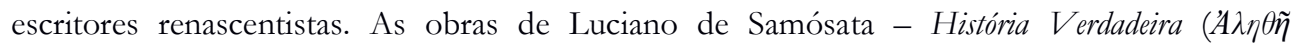

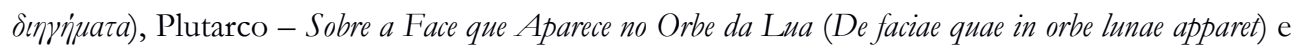
Cícero - O Sonho de Cipião (Somnium Scipionis) são a referência para todos os escritores que trataram de temas lunares. Essa tríade, em adição com os mitos platônicos de Fedro, Er e Fédon ${ }^{18}$, permeou a imaginação de diversos autores durante séculos. Alguns nomes como Dante, Rabelais, Cervantes e Ariosto possuem elementos de viagens extraordinárias, mas distantes ainda das viagens cósmicas a partir do XVII. Já que essas tradições sofreram uma mudança sutil quando foram incorporadas pela alquimia da "nova filosofia" dos séculos XVI e XVII. A rejeição da concepção sacerdotal do saber, a nova avaliação da técnica, o caráter hipotético ou realista do nosso conhecimento do mundo, a nova imagem de Deus como engenheiro ou relojoeiro e a introdução da dimensão do tempo na consideração dos fatos naturais, formam um conjunto de ideias, ou o Logosformel ginzburgiano, que fomentam o pensamento moderno.

Mais especificamente, a emergência da tese da não centralidade da Terra no pensamento da ciência moderna, o alargamento dos confins tradicionais do Universo, a afirmação da pluralidade dos mundos e da infinitude do cosmos e a invenção do telescópio suscitaram na cultura europeia não só exaltação e entusiasmo, mas também espanto e perturbação ${ }^{19}$. A nova

nossos mapas, mas longe desta terra para outro mundo, geralmente nos céus. Minhas viagens têm em comum um tema: cada uma delas é uma jornada extraterrestre na qual um marinheiro ou um grupo de marinheiros descobre um novo mundo, geralmente na lua ou nos planetas." Cf. Prologue. NICOLSON, Marjorie Hope. Voyages to the Moon. New York: The Macmillan Company, 1948.

${ }^{18} \mathrm{O}$ mito de Fedro é certamente uma matriz de muitas das viagens celestes. A imagem platônica de ascensão e queda da alma humana através das esferas celestes é fonte para diversas perspectivas posteriores. Além disso, a ideia de que a alma se assemelha a carros alados ofereceu algo aos inventores de "carros voadores" semicientíficos no século XVII. No mito de Er, Platão fez uso de um dispositivo que se tornou comum nas viagens cósmicas modernas, a saber, a alteração do ponto de referência. Assim, os viajantes cósmicos observarão a Terra a partir do ponto de vista dos corpos celestes, para os quais estão se dirigindo ou já estão localizados. Também do mito do Fédon, escritores posteriores de viagens cósmicas captaram algo da técnica de Platão ao expressar concepções científicas contemporâneas, através da linguagem da poesia e do mito.

${ }^{19}$ A ideia da ordem do mundo, da sua harmonia, da sua proporção, estava tradicionalmente ligada à imagem de um universo finito. Bem mais que a afirmação da mobilidade da Terra, as conclusões de caráter cosmológico que dela podiam derivar pareceram colocar em crise a própria ideia de que o Universo tivesse uma forma, que pudesse ainda ser interpretado como um sistema. Giordano Bruno colocou o mundo de Copérnico e os seus inumeráveis mundos dentro de um espaço infinito e homogêneo. A partir de uma perspectiva astrobiológica da tradição neoplatônica mágico-hermética, entrava em crise a noção de um universo ordenado e construído segundo leis imutáveis. (Conferir o excelente estudo de Frances Yates sobre a permanência dos temas hermético-platônicos no pensamento de Bruno e alguns contemporâneos. YATES, Frances A. Giordano Bruno e a tradição hermética. São Paulo: Editora Cultrix, 1995.) Essa proliferação de ideias novas parecia a Marin Mersenne, em 1644, o colocar à beira do fim do mundo. Cf. ROSSI, Paolo. A ciência e a filosofia dos modernos. São Paulo: Editora da Unesp, 1992, p. 215. Assim como no seu poema Anatomy of the World, de 1611, John Donne também questionava se o mundo não havia perdido a sua coerência e não tinha sido esmigalhado pelos seus átomos: "And new philosophy calls all in doubt,/ The element of fire is 
ciência fomentou a criatividade dos escritores de ficção, e esta impulsionou a imaginação dos cientistas, já que, nos dois séculos iniciais do pensamento moderno, os caminhos da ciência e da imaginação literária não estavam tão separados, ou seja, havia uma evidente imbricação entre ciência e ficção. Nas arguciosas palavras de Marjorie Hope Nicolson:

\begin{abstract}
E assim, devido à descoberta de Galileu sobre a natureza da Lua, as aerostáticas modernas surgiram; a crença perene de que o homem poderia voar surgiu novamente, passando da literatura para a ciência. Os poetas cantaram as glórias de um novo mundo; satiristas colocaram suas utopias lá; escritores imaginativos encontraram um novo tema para o romance; e os cientistas começaram a trabalhar seriamente, todos obcecados com uma ideia: que o homem pudesse voar para a Lua!20
\end{abstract}

Essa remodelação que permeava a cultura e definia a visão de mundo dos modernos foi organizada por Arthur O. Lovejoy em suas famosas cinco "teses cosmográficas"21. Elas representam de forma geral o conjunto de ideias e conhecimentos, partilhados pela sociedade, em especial os grupos intelectuais (isto é, um conjunto de pensadores que se viam como filósofos, mas que podemos organizar e sintetizar como cientistas, filósofos e literatos). A saber: a) a afirmação segundo a qual outros planetas do nosso sistema solar são habitados por criaturas vivas, sencientes e racionais; b) a demolição dos muros externos do universo medieval, quer estes se identificassem com a extrema esfera cristalina ou com uma região definida das estrelas fixas, e a dispersão destas estrelas nos vastos espaços irregulares; c) a ideia das estrelas fixas como sóis semelhantes ao nosso, todos ou quase todos circundados por sistemas planetários próprios; d) a hipótese de que também os planetas destes outros mundos fossem habitados por seres racionais; e) a asserção da efetiva infinidade do universo físico no espaço e do número dos sistemas solares nele contidos 22 . Longe de demarcar um consenso entre os pensadores da época, o que essas teses denotam é a condução que organiza o debate de ideias astronômico no início da Idade Moderna.

\title{
Kepler e a ficção científica
}

quite put out,/ The sun is lost, and th'earth, and no man's wit/ Can well direct him where to look for it./ And freely men confess that this world's spent,/ When in the planets and the firmament/ They seek so many new; they see that this/ Is crumbled out again to his atomies./ 'Tis all in pieces, all coherence gone,/ All just supply, and all relation".

${ }^{20}$ NICOLSON, Marjorie Hope. Cosmic Voyages. Journal of English Literary History, Vol. 7, No. 2, 1940, p.97.

${ }^{21}$ É justamente na mistura de temas lucrecianos, copernicanos, neoplatônicos e herméticos, característica de Nicolau de Cusa, Marcello Palingenio Stellato e Giordano Bruno, além de muitos outros autores distantes do rigor e da coerência do discurso científico galileano, que se deve procurar a presença dessas cinco ideias inovadoras ou "teses cosmográficas".

${ }^{22}$ LOVEJOY, Arthur O. The Great Chain of Being: a Study of the History of an Idea. Cambridge, Massachusetts and London: Harvard University Press, 2001, p. 121-123. 
É justamente de dentro dessa efervescência cultural que surge a primeira obra de viagem cósmica moderna, a saber, o Somnium, de Johannes Kepler (1571-1630). Impresso postumamente em 1634 na cidade de Frankfurt, o Somnium sive opus postbumum de astronomia lunari remonta a 1610 e tem sua origem numa primeira redação - perdida - escrita em 1593 em Tübingen ${ }^{23}$, para responder ao seguinte quesito: como os fenômenos celestes apareceriam para um observador situado na Lua? Inserido em um contexto de crescente encantamento com a Lua e a possibilidade de existência de vida extraterrestre, o Somnium se caracteriza por ser, no conjunto e simultaneamente, uma obra literária, alegórico-filosófica, uma autobiografia alusiva e uma obra de ciência ${ }^{24}$.

A narrativa é dividida em duas partes. A primeira é mais poética, enquanto a segunda é mais descritiva. Duracotus, que começa a narrativa, é um duplo fictício de Kepler. Ele não se lembra de seu pai, um pescador, que morreu aos 150 anos quando seu filho ainda era bebê. Fiolxhilda, a mãe de Duracotus, é o reflexo da bruxa Katharina, mãe de Kepler. É uma mulher sábia, que se sustenta vendendo aos marinheiros saquinhos de ervas contendo encantos misteriosos. Infelizmente, Fiolxhilda é uma mulher de temperamento ingovernável. Numa ocasião em que o filho bisbilhota uma de suas sacolas, ela, como punição, o entrega impulsivamente a um capitão marítimo em troca de dinheiro. Por um tempo, a mãe desaparece da história e seguimos a trilha do filho, a quem Kepler retrata com simpatia. Nós o acompanhamos em uma viagem entre a Noruega e a Inglaterra e finalmente chegamos com ele na Dinamarca. Muito afetado pelo mar agitado, o jovem revela-se pouco útil para o capitão, que decide se livrar desse fardo. Como o capitão se dirigia à ilha onde habitava o astrônomo dinamarquês Tycho Brahe, ele resolve despachar o garoto como mensageiro, prometendo voltar mais tarde. Durante algum tempo, Duracotus permanece com o grande astrônomo, que prenuncia no jovem um futuro promissor. De modo que quando o capitão finalmente retorna, ele se recusa a enviar o jovem de volta para

${ }^{23}$ KEPLER, Johannes. Somnium, seu opus posthumum De astronomia lunari. Frankfurt: 1634. Utilizamos a tradução do latim para o inglês de Normand Raymond Falardeau. In. FALARDEAU, Normand Raymond. The Somnium Astronomicum of Johann Kepler Translated, with Some Observations on Various Sources. Submitted to the Faculty of Creighton University in Partial Fulfillment of the Requirements for the degree of Master of Arts in the Department of Latin. Omaha, 1962. Essas datações são organizadas por Marjorie Hope Nicolson. Ela propõe que a provável data de escrita do Somnium em sua forma final seja 1610. Também traça os vestígios e os fluxos que esse texto teve principalmente na Inglaterra alguns anos antes, em especial a recepção que John Donne teve ao compor seu Ignatius His Conclave. O próprio Kepler teve conhecimento dessa recepção e comentou: "I suspect that the author of that impudent satire, the Conclave of Ignatius, had got hold of a copy of this little work [a primeira versão do Somnium], for he pricks me by name in the very beginning. Further on, he brings up poor Copernicus to the judgment seat of Pluto - if I don't mistake, the approach to that is through the yawning chasms of Hecla" Cf. NICOLSON, Marjorie Hope. Kepler, the Somnium, and John Donne. Journal of the History of Ideas, Vol. 1, No. 3, 1940, p. 268.

${ }^{24}$ Arthur Koestler exprimiu precisamente a particularidade do Somnium: "Todos os dragões que assediaram sua vida [Kepler] - desde a bruxa Fiolxhilda com seu marido desaparecido até as pobres criaturas reptilianas sempre em fuga que se despojam de sua pele e desejam tanto aquecer-se num Sol inumano - estão todos aqui, projetados num cenário cósmico de precisão científica e de rara beleza”. KOESTLER, Arthur. The Sleepwalkers: A History of Man's Changing Vision of the Universe. New York: The Macmillan Company, 1959, p. 419. 
casa. Assim, Duracotus permanece aprendendo o conhecimento da nova astronomia, "a mais divina das ciências".

Depois de cinco anos, Duracotus volta para casa, feliz por encontrar sua mãe ainda viva e arrependida do acesso impulsivo em que havia mandado o filho embora. Para sua surpresa, o jovem descobre que sua mãe era de fato uma mulher sábia, tão sábia quanto Tycho Brahe no conhecimento dos céus. De alguma maneira, Fiolxhilda instruiu-se pela experiência em tudo o que Tycho conhecia na teoria. Após um período de hesitação, ela finalmente confia ao filho a fonte de seu conhecimento. Assim, Duracotus descobre que sua mãe estava ligada aos "demônios de Levania" 25 , os espíritos da Lua. Ela revela que pode se comunicar e convocá-los ocasionalmente, além de asseverar ser com eles que os mortais escolhidos podem viajar para o mundo distante. Certa noite, Duracotus finalmente alcança seu desejo. Em uma primavera, com a Lua crescente e o planeta Saturno alinhado no signo de Touro, qualificam-se os presságios auspiciosos:

\begin{abstract}
Minha mãe, afastando-se de mim na encruzilhada mais próxima e soltando poucas palavras, apresentou seu pedido em um intenso clamor. Depois que ela completou o cerimonial, ela retornou e, exigindo silêncio com a palma da mão direita estendida, sentou-se junto a mim. Mal tínhamos enrolado nossas cabeças com um pano (como era o costume), quando eis que surgiu o estertor de uma voz rouca e cantarolada, a qual imediatamente começou a relatar a história a seguir, mas na língua islandesa ${ }^{26}$.
\end{abstract}

Assim termina a primeira seção do Somnium. Apesar da linguagem em moldes de lenda e superstição, essa parte da obra é claramente baseada na própria vida de Kepler, com alusões pouco disfarçadas que são prontamente reconhecíveis. O paralelismo, embora não exato, é claramente intencional. Kepler estava contando uma história velada de sua própria vida ${ }^{27}$. Mas Duracotus é também o símbolo da ciência, gerada pela "experiência ignorante" ou pela "prática empírica" de Fiolxhilda ${ }^{28}$.

\footnotetext{
25 No original é "Daemon". Utilizamos demônio pela similaridade fonética, porém a palavra latina Daemon está mais associada a uma divindade, espírito ou entidade.

${ }^{26}$ KEPLER, 1962, op. cit., p. 21.

${ }^{27}$ Marjorie Hope Nicolson denota que a mãe de Kepler foi bem retratada em Fiolxhilda. Quase analfabeta e de classe social diferente do marido, ela era, no entanto, uma mulher de realizações notáveis, uma mulher sábia no melhor sentido da palavra. Ela também era, como Fiolxhilda, uma mulher de temperamento imperdoável, brigando constantemente com os vizinhos. O início da vida de Duracotus diferia do de seu criador, já que o próprio Kepler conseguiu uma educação convencional, incluindo treinamento em teologia em Tübingen, onde ficou sob a influência de Michael Maestlin e aprendeu as teorias de Copérnico, das quais ele nunca se afastou. Como Duracotus foi aprendiz por cinco anos de Tycho Brahe, em Uraniborg, a ilha na qual o astrônomo dinamarquês havia estabelecido seu "castelo dos céus". Kepler também se tornou assistente de Tycho. Como na obra, na realidade, Tycho e Kepler trabalharam juntos por alguns anos e, com a morte de Tycho em 1601, Kepler se tornou herdeiro da rica coleção de papéis e anotações em que Tycho deixou muitas de suas descobertas para a posteridade. Cf. NICOLSON, 1948, op. cit., p. 43-44.

${ }^{28}$ Cf. NICOLSON, 1940, op. cit., p. 259-267.
} 
$\mathrm{Na}$ segunda parte da obra o narrador, que fala em primeira pessoa, muda imprevistamente. O novo personagem que começa a narrar é o Demônio de Levania (a Lua), que descreve a viagem e os aspectos astronômicos, sociais e geográficos da Lua. Ele, que aparece ao ser convocado por Fiolxhilda, ensina Duracotus que os mortais só podem alcançar a Lua por meios sobrenaturais: eles devem ser carregados por demônios. Em sua descrição do voo, Kepler usa o mesmo dispositivo literário de Cervantes. Duracotus recebe um anestésico para que ele se lembre pouco do percurso ${ }^{29}$. No entanto, esse não era um mero recurso literário conveniente para Kepler, como havia acontecido com o escritor anterior. Kepler não estava tentando sair de dificuldades. Como mostram suas notas extensas, ele estava considerando o provável efeito da gravidade no corpo do homem ao deixar o "poder atraente" da Terra. De fato, algumas das importantes teorias da gravitação de Kepler podem ser encontradas em diversas passagens do Som$\operatorname{nium}^{30}$.

Ademais, Kepler ponderou também sobre o efeito do ar rarefeito sobre os seres humanos. Seus demônios deveriam se proteger contra a "respiração proibida" dos mortais, utilizando “esponjas umedecidas e aplicadas nas narinas". Uma vez que o viajante se elevasse, subisse ao ar e finalmente passasse pelo "orbe da virtude" da Terra, ele se descobriria em um distrito intermediário no qual "o transporte se tornava mais fácil" e os demônios não precisam mais, como a princípio, usar a força sobre seus passageiros.

A viagem no Somnium é uma mistura de fantasia e realismo, mas quando o demônio descreve a Lua, a fantasia cessa. Nessa segunda parte, o objetivo de Kepler é apresentar, a partir de uma descrição minuciosa, todos os pormenores que constituem a Lua e seus habitantes. Os personagens anteriores - Fiolxhilda e Duracotus - desaparecem, para dar lugar a uma espécie de "tratado sobre a Lua". Essa parte "científica" da obra, que é amplamente dominante, tende a extrair do exemplo da Lua uma argumentação a favor do movimento da Terra. Kepler é um autor cientista, por isso seu modo de guiar o leitor pela Lua é a de um verdadeiro cientista da modernidade. Os habitantes da Lua têm dimensões enormes e "natureza serpentina". Têm vida brevíssima e se escaldam ao tremendo calor do Sol para depois refugiar-se em frias cavernas e

\footnotetext{
${ }^{29}$ Quixote lembra que os demônios que levaram Torralba em seu voo noturno lhe deram um anestésico que amorteceu a dor da viagem - e, convenientemente para o autor, permitiu que o viajante esquecesse muitos detalhes de sua experiência. Cf. capítulo XLI "Da vinda de Cravelinho, mais o fim desta dilatada aventura" da segunda parte de CERVANTES Saavedra, Miguel de. D. Quixote de La Mancha. São Paulo: Nova Aguilar, 2015, p. 839-847. Para essa herança de Cervantes em Kepler (e em outros autores de viagens cósmicas), conferir NICOLSON, 1948, op. cit., p. 18-19.

${ }^{30}$ Entre 1620 e 1630, Kepler adicionou 223 notas, mais extensas que o próprio Somnium, que complementam e explicam a obra. Kepler fornece longas explicações das teorias de Galileu e Tycho Brahe, suas próprias reflexões pessoais e vários comentários sobre como, por que e em que contexto social sua história ficcional foi escrita. Entre as notas 70 e 80, há diversos apontamentos sobre as forças magnéticas que um corpo tem na Terra e na Lua. Por exemplo, em uma das notas, ele considera que a atração entre dois corpos celestes era inversamente proporcional à distância e não ao quadrado da distância, como Isaac Newton (1643-1727) viria a propor posteriormente.
} 
fendas. Na descrição do mundo físico nos encontramos dentro daquele universo que foi revelado pelo telescópio ${ }^{31}$ :

Para os habitantes da Terra, a nossa Lua, quando nasce cheia e avança sobre as casas mais distantes, parece assemelhar-se ao arco de um barril. Quando se alça no meio do céu, parece a imagem de um rosto humano. Os subvolvanos, ao contrário, a sua Volva aparece sempre no meio do céu. Pouco menor que o quádruplo do diâmetro da nossa Lua, de modo que, comparando os dois discos, a Volva deles é quinze vezes maior que a nossa Lua (...) Para os habitantes da Lua, é evidente que a nossa Terra, que é a sua Volva, gire, mas que a sua Lua seja imóvel. Se alguém afirmar que os sentidos selênicos da minha população lunar se enganam, com igual direito respondem que os sentidos terrestres dos habitantes da Terra são desprovidos de razão $\mathrm{O}^{32}$

O mundo lunar de Kepler é tão estranho para nós quanto a Lua parecia para Galileu. Estações, duração do dia e da noite, clima, todos são bem diferentes dos da Terra. Levania é dividida em duas zonas, "Subvolva" e "Privolva". O hemisfério Subvolva está sempre voltado para a Terra (Volva), enquanto o Privolva está voltado para o lado oposto à Terra. No Privolva, “a noite dura 15 ou 16 dias e é terrível com sombras ininterruptas". Nesta zona o Sol nunca brilha e tudo é rígido com frio. Em Subvolva, o clima é um pouco menos intolerável. Topograficamente, o mundo da Lua é muito parecido com o terráqueo, exceto que tudo está em uma escala exagerada. As montanhas possuem alturas incríveis, as fissuras e vales mais profundos do que qualquer desfiladeiro terrestre.

Adotando um ponto de vista a partir da perspectiva lunar, Kepler oferece persuasivos argumentos em favor da verdade copernicana, ao mesmo tempo em que nos deixa entrever algo da complicada personalidade do autor e está na origem de um novo e bem sucedido gênero literário, isto é, a ficção científica. Como salientou Marjorie Hope Nicolson, a antiga tradição literária das viagens lunares, derivada de Luciano, Plutarco e Cícero, transforma-se nas mãos de $\operatorname{Kepler}^{33}$. Essa tradição estimula a imaginação de Kepler, que propõe um enfoque que só poderia

\footnotetext{
${ }^{31}$ Com o uso do telescópio, Galileu descobriu "novos planetas" (hoje se sabe que eram satélites de Júpiter) e descreveu a visão da Lua como uma superfície desigual, com protuberâncias e sinuosidades (não era mais lisa e lustrosa como apresentada na tradição literária). Essas novidades deram uma nova perspectiva e aguçaram a mente dos contemporâneos. Marjorie Hope Nicolson apresenta com primor e beleza essa nova concepção que o telescópio proporcionou: "Luciano havia imaginado um mundo na Lua; Plutarco e Cícero haviam pressupostos pela lógica. Mas Galileu havia visto com seus olhos". NICOLSON, 1948, op. cit., p. 24. Conferir também: NICOLSON, Marjorie Hope. Milton and the Telescope. Journal of English Literary History, Vol. 2, No. 1, 1935.

32 KEPLER, 1962, op. cit., p. 23.

33 É importante destacar que Kepler não é o inventor genial romântico que criou uma narrativa de viagem lunar a partir da pura imaginação. Muito pelo contrário, como intelectual moderno, essas referências faziam parte do seu arcabouço cultural e eram amplamente difundidas entre seus contemporâneos. A noção de invenção nos séculos XVI, XVII e XVIII pressupõe a memória de tópicas já conhecidas do público, que faz da sua repetição um critério positivo de avaliação de discursos. A concepção romântica de invenção como originalidade só está associada a partir do século XIX. Além disso, o próprio Kepler havia realizado uma tradução para o latim da obra de Plutarco. (No início do século XVII, as obras de Luciano, Cícero e
} 
estar em uma obra do mundo moderno. Pois discute efeitos da gravidade e o "poder atrativo" da Terra, além de conjecturar o efeito do ar rarefeito sobre o corpo humano. Ou seja, a sobrevivência do tema não esclarece sozinha o motivo da sua emergência de popularidade e nem a tradição literária por si explica as características peculiares das viagens cósmicas a partir do século XVII. Isso só se desvela como consequência da ciência, em especial da nova astronomia e o seu conjunto de ideias em debate na época, como apontado por Lovejoy. Assim, o Somnium, ao alinhavar temas de uma tradição especificamente ficcional com uma abordagem científica, tornase a origem e fonte de um novo tema literário: o das viagens científicas à Lua. É familiar a todos os escritores de viagens cósmicas nos séculos XVII, XVIII e XIX, de modo que por mais de um século se tornou o padrão para as obras de viagens cósmicas ${ }^{34}$.

Nestas primeiras reflexões, procuramos identificar as diferenças, a complexidade e as vicissitudes do despontar da concepção de ficção científica. Para isso, utilizamos a obra Somnium, de Johannes Kepler, como vestígio e indício, com o propósito de ponderar sobre a imbricação existente entre ciência e literatura no início da idade moderna. Procuramos destacar como as ideias relativas à pluralidade e habitabilidade dos mundos e à possibilidade de viagens lunares e cósmicas são exploradas nesse contato íntimo entre ciência e literatura. De modo que essa conexão é fundante de um novo gênero narrativo, a ficção científica.

Nosso objetivo foi inscrever este estudo na história das ideias entendida como um campo interdisciplinar ${ }^{35}$. Por isso, ao propor um exercício de hermenêutica histórica sobre o Somnium de Kepler, pretendemos levar em conta, pelo menos em parte, as transmissões e recepções do tema enquanto trajetória de uma ideia no tempo. Como nos instruiu Gadamer, a abordagem da tradição pelos historiadores deve incluir, então, uma postura de "abertura". Ao estranhamento com o passado deve se somar a capacidade de "ouvir o que ele tem a dizer". Deve, portanto, comportar aquilo que Gadamer chama de "consciência da história efeitual" (Wirkungsgeschichte Bewusstsein), a saber, a consciência de que a tradição histórica não está morta inteiramente, mas está viva em nossa cultura, em nossos "preconceitos". Ela deixa traços e fragmentos em cada nova assimilação, que podem ser acessados. Os textos escritos e fenômenos históricos possuem relevância para os homens em geral e para a historiografia em particular em decorrência do efeito que causaram na experiência temporalizada e somente deste modo podem ganhar sentido.

Plutarco estavam em ampla circulação, inclusive com traduções para as línguas vernáculas). Cf. Capítulo 1: The Discovery of a New World de NICOLSON, 1948, op. cit.

34 O Somnium foi conhecido, por exemplo, por Cyrano de Bergerac, Bernard Le Bouyer de Fontenelle, David Russen, Samuel Butler, Jules Verne, Camille Flammarion e H. G. Wells.

35 Concomitantemente, endossamos a proposta enunciada por Gildo Magalhães de que história das ciências pode realizar a verdadeira interdisciplinaridade, pois pode funcionar como uma ponte que permite transpor o abismo entre humanidades e ciências naturais. Cf. MAGALHÃES, GILDO. Por uma dialética das controvérsias: o fim do modelo positivista na história das ciências. Estudos Avançados, Vol. 32, No. 94, 2018. 
E esse é o âmbito da nossa proposta de hermenêutica histórica, ou seja, a partir da tradição relativa às narrativas de viagens, tencionamos identificar as persistências e metamorfoses dos resquícios na obra de Kepler e, com isso, desenhar os contornos iniciais de um novo gênero literário. 